Family Profile No. 3, 2019

\title{
Marriage-to-Divorce Ratio in the U.S.: Geographic Variation, 2017
}

\section{Author: Valerie J. Schweizer}

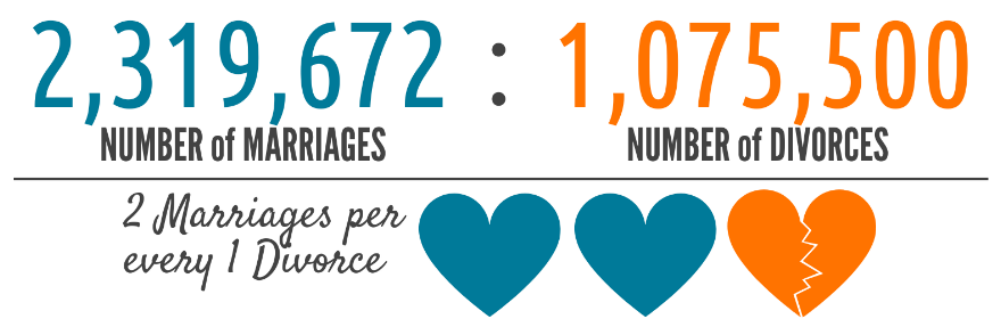

Marriage to Divorce Ratio in the U.S., 2017

- In 2017, there were slightly more

Figure 1. Women's Marriage to Divorce Ratio, 1970 to 2017 than two marriages for every one divorce in the United States (marriage to divorce ratio $=2.2$ ). There were 2,319,672 marriages and 1,075,500 divorces.

- Although the ratio has not returned to what it was in 1970 when there were three marriages per one divorce, it is at its highest point since the ACS began collecting detailed marriage and divorce data in 2008.

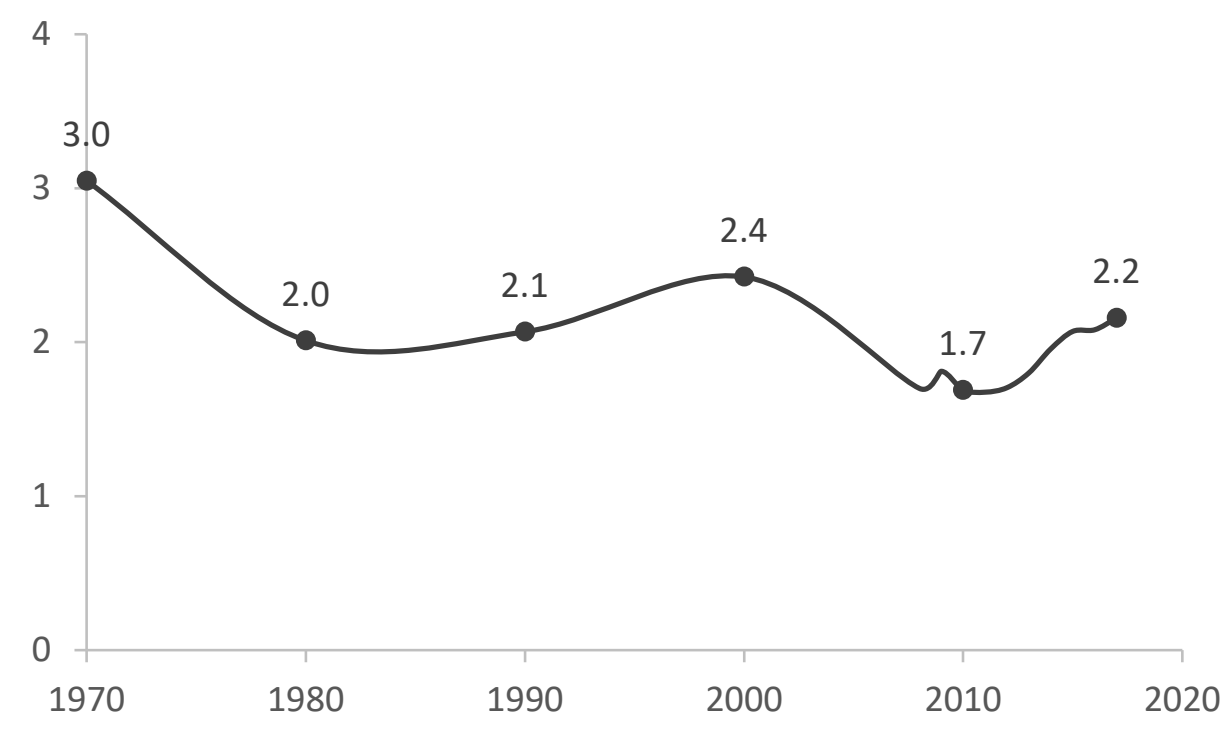

Source: NCFMR analyses of 970-2000, National Center for Health Statistics; 2008-2017, U.S. Census Bureau, American Community Survey 1-yr est

Five Highest and Lowest Marriage to Divorce Ratios, 2017

- All states have a greater number of marriages than divorces. For 2017, the top three states in the marriage-todivorce ratio are the District of Columbia (5.9), Hawaii (3.4), and Alaska (3.3). There were at least three marriages per one divorce in these states.

- The states with the lowest marriage to divorce ratio are Maine (1.3), Alabama (1.4), and Rhode Island (1.5).
Table 1. Highest and Lowest Marriage to Divorce Ratios, 2017

\begin{tabular}{|ccc|}
\hline Rank & State & Marriage Divorce Ratio \\
1 & District of Columbia & 5.9 \\
2 & Hawaii & 3.4 \\
3 & Alaska & 3.3 \\
4 & Wyoming & 3.0 \\
5 & Utah & 3.0 \\
& U.S. & 2.2 \\
47 & Arkansas & 1.6 \\
48 & Delaware & 1.6 \\
49 & Rhode Island & 1.5 \\
50 & Alabama & 1.4 \\
51 & Maine & 1.3 \\
\hline
\end{tabular}

Source: NCFMR analyses of U.S. Census Bureau, American Community Survey 1-yr est. 
- The states with a significantly higher marriage to divorce ratio than the national average were the District of Columbia, Hawaii, Alaska, Wyoming, Utah, Kansas, Montana, North Dakota, New York, Illinois, Texas, Wisconsin, California, South Dakota, Pennsylvania, Ohio, and lowa.

- Almost half of states (48\%) saw an increase in the marriage-to-divorce ratio from 2015 to 2017 . Vermont experienced the largest increase in the ratio of marriage to divorce, shifting from 1.9 to 2.1 .

- About one-quarter of states experienced a decrease in the marriage-to-divorce ratio. Delaware experienced the largest decrease in the ratio of marriage to divorce, from 3.0 to 1.6 marriages per every divorce from 2015 to 2017.

- One-quarter (26\%) of states had almost the same marriage-to-divorce ratio in 2017 as they did in 2015. These states were Arizona, Arkansas, California, Florida, Idaho, Kentucky, Maryland, Minnesota, New Mexico, Oklahoma, South Carolina, South Dakota, and Virginia.

Figure 3. Geographic Variation of Women's Marriage to Divorce Ratio in the U.S., 2017

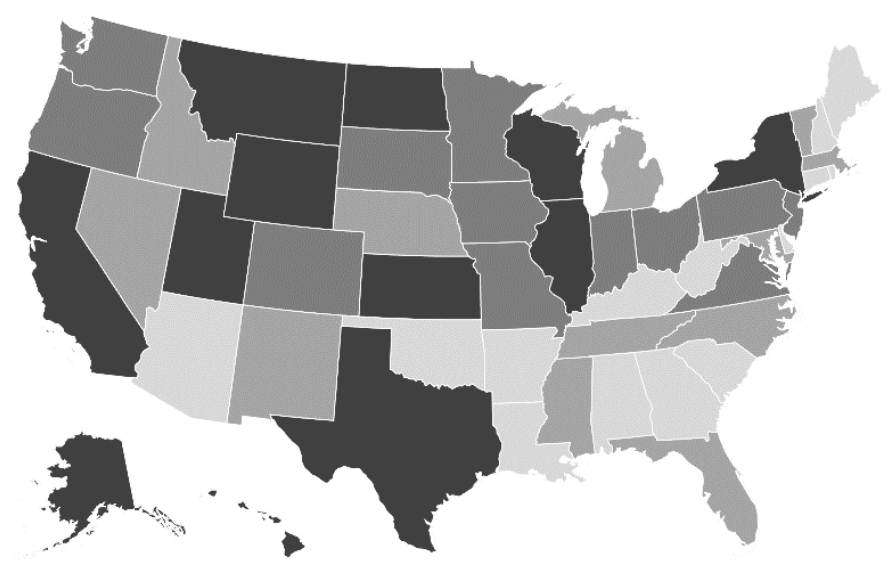

Source: NCFMR analyses of Source: U.S. Census Bureau, American Community Survey 1-yr est.
Figure 2. State Variation in the Marriage to Divorce Ratio Among Women Aged 15+ by quartile, 2017

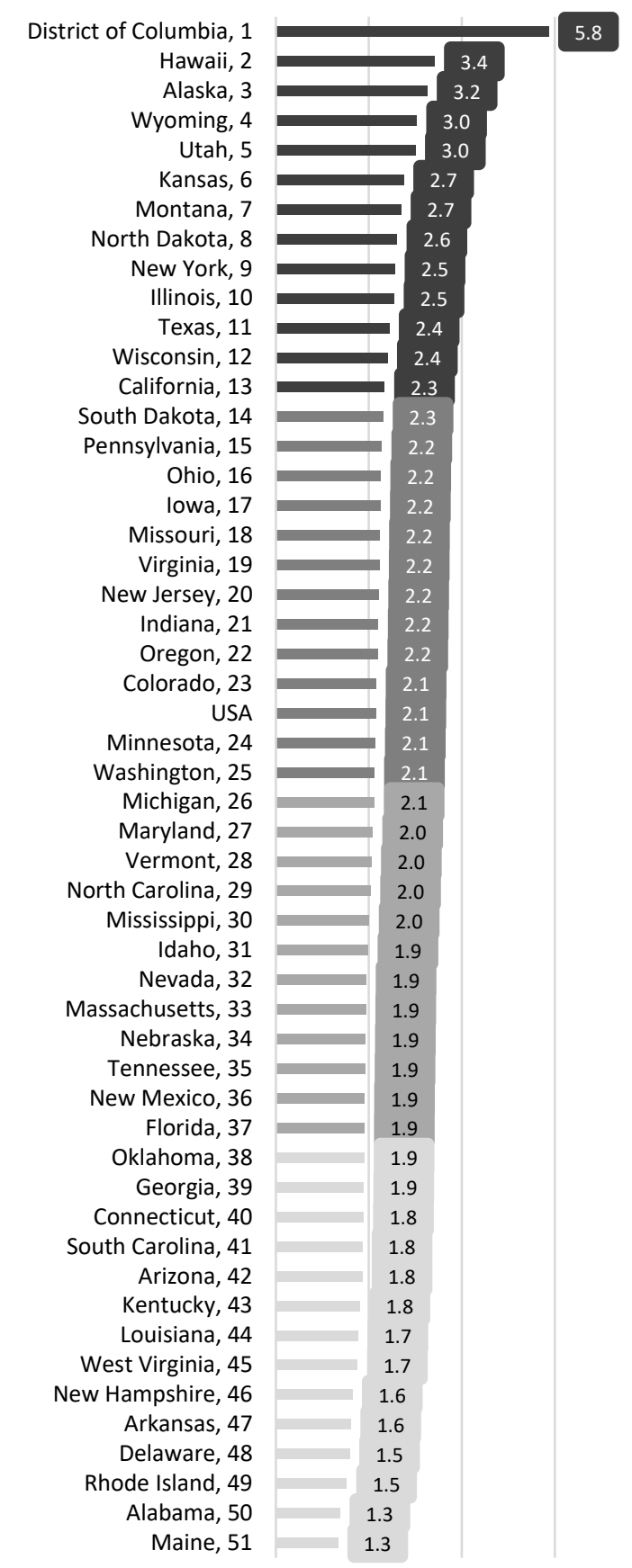

References:

Clarke, S. C. (1995). Advance Report of Final Marriage Statistics, 1989 and 1990. Monthly Vital Statistics Report, 43(12), Supp. National Center for Health Statistics. http://www.cdc.gov/nchs/data/mvsr/supp/mv43_12s.pdf

National Center for Health Statistics (1974). Summary Report Final Marriage Statistics, 1970. Monthly Vital Statistics Report, 23(2) (Supp. 1). U.S. Department of Health, Education, and Welfare. http://www.cdc.gov/nchs/data/mvsr/supp/mv23_02s1acc.pdf

National Center for Health Statistics (1983). Advance Report of Final Marriage Statistics, 1980. Monthly Vital Statistics Report, 32(5). U.S. Department of Health and Human Services. http://www.cdc.gov/nchs/data/mvsr/supp/mv32_05s.pdf

National Center for Health Statistics (2001). Births, Marriages, Divorces, and Deaths: Provisional Data for January-December, 2000. National Vital Statistics Reports, $49(6)$. Associated Table 3. Department of Health and Human Services, Centers for Disease Control and Prevention. http://www.cdc.gov/nchs/data/nsvr/nsvr49/49_06_12_03.pdf

\section{Suggested Citation:}

Schweizer, V. J. (2019). Marriage-to-divorce ratio in the U.S.: Geographic variation, 2017. Family Profiles, FP-19-03. Bowling Green, OH: National Center for Family \& Marriage Research. https://doi.org/10.25035/ncfmr/fp-19-03.

\begin{tabular}{|c|c|c|}
\hline :GSU. & $\begin{array}{l}\text { National Center for } \\
\text { Family \& Marriage Research }\end{array}$ & $\begin{array}{l}\text { http://www.bgsu.edu/ncfmr } \\
\text { ncfmr@bgsu.edu }\end{array}$ \\
\hline BOWLING GR & EN STATE UNIVERSITY & (419) $372-3119$ \\
\hline
\end{tabular}

This project is supported with assistance from Bowling Green State University. From 2007 to 2013, support was also provided by the U.S. Department of Health and Human Services, Office of the Assistant Secretary for Planning and Evaluation. The opinions and conclusions expressed herein are solely those of the author(s) and should not be construed as representing the opinions or policy of any agency of the state or federal government. 